\title{
Utilization of information and communication technology (ICT) among sexually transmitted disease clinics attendees with coexisting drinking problems
}

Xingdi Hu${ }^{1 *}$, Virginia J Dodd ${ }^{2}$, James C Oliverio ${ }^{3}$ and Robert L Cook ${ }^{1,4}$

\begin{abstract}
Background: Alcohol misuse remains a major risk factor for contracting sexually transmitted diseases (STDs) not typically addressed in STD clinic settings. Information and communication technology (ICT) can offer new avenues to deliver evidence-based screening and treatment for problematic drinking, however, few data exists regarding the utilization of ICT among STD clinic attendees with coexisting drinking problems. The objectives of this study are to identify STD clinics attendees with hazardous drinking, to examine socio-demographic factors associated with ICT use, and to explore individuals' interests in engaging in ICT-based health interventions.
\end{abstract}

Methods: Cross-sectional questionnaires examining alcohol consumption and ICT use were administered to 396 persons attending two non-urban STD clinics. Descriptive statistics for ICT use were calculated for both hazardous drinkers and the entire sample. Multivariable logistic regression models among hazardous drinkers identified factors significantly associated with use of each kind of ICT.

Results: The mean age of the 396 participants was 25 years, 66\% were females and 60\% were African-Americans. One third of the sample met the criteria of hazardous drinking. ICT use in hazardous drinkers included 94\% reporting having internet access at least monthly, $82 \%$ reporting having an email account, $85 \%$ reporting currently owning a cell phone, and $91 \%$ reporting use of any cell phone application. More than two thirds (73\%) of hazardous drinkers were willing to play health-related video games during clinic waiting time, slightly higher than the entire sample (69\%). Multivariable analyses indicated that younger age were significantly related to monthly internet use, and multifunction cell phone use, while being males and younger age were significantly associated with monthly video game playing.

Conclusions: Our study demonstrates commonality of ICT use among STD clinic attendees with hazardous drinking, indicating the viability of using ICT to assist screening and behavioural intervention for alcohol misuse in STD clinic settings. Future research is needed to demonstrate the effectiveness of ICT-based health behavioural interventions in the STD clinic settings or other venues that serve populations at high risk for substance abuse, HIV or other STDs.

Keywords: Information and communication technology (ICT), Hazardous drinking, Substance abuse, Sexually transmitted diseases (STDs), Cell phone, Email, Internet, Video games, Digital divide

\footnotetext{
* Correspondence: qmshjwhx@phhp.ufl.edu

'Department of Epidemiology, University of Florida, Gainesville, FL, USA

Full list of author information is available at the end of the article
} 


\section{Background}

Hazardous alcohol consumption could impair judgement and decision-making, leading people to engage in risky sexual behaviours, such as having multiple sexual partners and/or having sex without condoms. These behaviours further lead to increased risk of sexually transmitted diseases (STDs) [1-3]. Previous studies have underscored a high rate of alcohol consumption among people attending STD clinics [4-6]. For instance, Cook et al. found a high rate of binge drinking (48.0\% of men and 39.6\% of women) among a sample of young adults attending a STD clinic, with $28.3 \%$ meeting the criteria for alcohol use disorder, a prevalence much higher than that found in the general population [7]. Providing screening and behavioural interventions for hazardous drinking in STD clinics offers a unique opportunity to address both hazardous drinking and risky sexual behaviours, and these interventions have the potential to reduce transmission of STDs. However, most staff members in STD clinics traditionally lack training in screening and management of problematic drinking. As a result, they do not often identify coexisting hazardous drinking and provide adequate care. Innovative methods, like information and communication technology (ICT), could provide a new avenue to deliver evidencebased screening and brief interventions for hazardous drinkers at high-risk of STDs. Such interventions could allow for consistent screening for alcohol use, are inexpensive, potentially engaging, and can minimize staff burden required for intervention delivery.

For substance abuse treatment, a number of ICT-based applications have been developed and have shown promising results [8-10]. For example, a recent meta-analysis found that computer-based treatments were effective in reducing alcohol consumption [11]. However, little is known regarding the pattern of ICT use among problematic drinkers who seek testing/treatment for STDs. Samal et al. examined internet and cellular phone use among 200 women attending an urban STD clinic and found $80 \%$ reporting internet use, and 93\% having a cell phone [12]. Another study conducted in 2006 reported similar level of internet use (80\%) among 251 STD clinic attendees [13]. These studies, although providing important preliminary estimates of ICT use in general STD highrisk population, did not estimate the prevalence of hazardous drinking, or characterize rate of ICT use among the hazardous drinkers, or tried to determine technology types other than cell phones or internet. Therefore, we conducted a survey among attendees of two non-urban STD clinics with the purpose of identifying those with hazardous drinking, examining their accessibility and utilization of ICT, exploring factors associated with their ICT use, and providing baseline estimates in terms of willingness to adopt ICT-based health interventions.

\section{Methods}

From January 13, 2009 to March 10, 2009, at two public county health departments in Florida, USA, consecutive persons presenting at the STD clinics were asked to complete an anonymous, self-administered questionnaire. To ensure privacy, participants completed the questionnaire in a private room or a designated area of the clinic. To ensure anonymity, they sealed completed questionnaires in an envelope and then placed the envelope into a box with a slot on top. This study was approved by the institutional review boards of the University of Florida and the Florida Department of Health.

The first nine items of the survey assessed sociodemographic characteristics, including gender, age, race, education, employment status, marital status, and health insurance coverage. Individual alcohol consumption was measured by the Alcohol Use Disorders Identification Test (AUDIT). AUDIT has been widely used to identify patients with a wide spectrum of alcohol use disorders $[14,15]$. In addition to AUDIT, we also asked participants about frequency of engaging in binge drinking, defined as at least five (male) or four (female) drinks per occasion [16]. Based on both AUDIT and the binge drinking question, persons were classified as hazardous drinkers if AUDIT $\geq 8$ or binge drinking was reported at least once monthly. Marijuana and other drug use were also assessed, including cocaine or crack, stimulants, anxiety medication or sedatives, prescription pain medications, hallucinogens, inhalants, and opioids.

The rest of the survey asked locally-developed questions about the type and the frequency of ICT use. "Monthly internet use" was defined as at least monthly access to internet at home, school, libraries, or work. "Daily email use" was defined as having and checking an email account at least once every day. Questions assessing cell phone use asked whether participants currently owned a cell phone, and whether they used any common cell phone functions, such as sending text messages, downloading ringtones, downloading games or taking pictures via the phone camera. Information to distinguish smartphone use from other cell phone types was not specifically asked in this survey. "Multifunction cell phone use" was defined as participants reporting both owning a cell phone and using any of above cell phone functions. "Monthly video game playing" was defined as video game playing at least once a month through various video game consoles (i.e. Nintendo Wii, XBOX360, Playstation2/3, Gameboy, and PSP).

To explore potential acceptability of using video game for health promotion, participants were asked whether they would be willing to play any health-related video game during waiting time at the STD clinic. We also assessed individuals' privacy concern of ICT by asking whether they agreed with statements that cell phone 
conversations and text messaging were private. In the end, among those who reported access to these technologies, we explored their willingness to receive reminders via email or text messages about STD test results readiness.

We analysed data using the statistical package SAS 9.2. Descriptive statistics for variables of interests, including demographics and ICT use, were presented for both hazardous drinkers and the entire sample for comparison purpose. Fishers' exact test and two-way Pearson chi-square analyses were performed to assess associations of use of each ICT modality with socio-demographic characteristics. Age was categorized into 14-24, 25-34, and 35 or older. Race was categorized into white, black, Hispanic, and other racial group, including Asian, Native Hawaiian/ Pacific Islander, and American Indian/Alaskan Native. The highest level of education attained was classified into high school degree/GED or less, some college or vocational degree, and college degree or more. Marital status was categorized into three levels: being married, member of unmarried couple, and single. We generated two dichotomous variables for employment (employed/ unemployed) and insurance status (insured/uninsured). Variables achieving statistical significance in the bivariate analyses were included in the multivariable logistic regression models which assessed their adjusted associations with ICT use while controlling for other covariates. Multivariable analysis was performed only among those meeting the criteria of hazardous drinking.

\section{Results}

\section{Sample characteristics}

Of the 489 persons approached by research staffs, eightyone percent $(n=396)$ completed the questionnaires and the mean age was 25 years old $(\mathrm{SD}=8.3)$. Most of the participants were females $(66 \%, \mathrm{n}=258)$, African American $(60 \%, \mathrm{n}=234)$, unemployed $(59 \%, \mathrm{n}=231)$, had a high school degree or less $(57 \%, \mathrm{n}=223)$, and were uninsured $(50 \%, n=199)$. Approximately one third of the total sample $(n=126)$ met the criteria for hazardous drinking. Participants were significantly $(\mathrm{P}<0.05$ or $\mathrm{P}<0.01)$ more likely to report hazardous drinking if they were males, white, of older age (25+ years), had higher educational status, and/or were positive for self-reported use of marijuana or other drugs in the past year (Table 1). Fortyseven percent of the entire sample reported marijuana use in the past 12 months and 13\% reported other drug use while among hazardous drinkers these proportions increased to $69 \%$ and $27 \%$, respectively.

\section{ICT use}

Data describing ICT use were presented in Table 2. Among 126 hazardous drinkers, 94\% reported internet use at least monthly, $82 \%$ reported owning an email account, and 58\% reported daily email use. Eighty-five
Table 1 Socio-demographic characteristics of the study population $(\mathrm{N}=396)$

\begin{tabular}{|c|c|c|c|}
\hline \multirow[b]{2}{*}{ Characteristics } & \multirow[b]{2}{*}{$\begin{array}{l}\text { Total }^{a} \\
(\mathrm{n}=396) \\
\mathrm{N}(\%)\end{array}$} & \multicolumn{2}{|c|}{ Hazardous drinkers ${ }^{b}$} \\
\hline & & $\begin{array}{l}\text { Yes } \\
(n=126) \\
N(\%)\end{array}$ & $\begin{array}{l}\text { No } \\
(n=264) \\
N(\%)\end{array}$ \\
\hline \multicolumn{4}{|l|}{ Gender } \\
\hline Male & $134(34)$ & $66(52)^{c}$ & $64(25)$ \\
\hline Female & $258(66)$ & $60(48)$ & $196(75)$ \\
\hline \multicolumn{4}{|l|}{ Age (years) } \\
\hline $14-24$ & $261(68)$ & $74(60)^{d}$ & $185(73)$ \\
\hline $25-34$ & $76(20)$ & $33(27)$ & $41(16)$ \\
\hline $35+$ & $46(12)$ & $17(13)$ & $27(11)$ \\
\hline \multicolumn{4}{|l|}{ Race } \\
\hline White & $104(27)$ & $55(44)^{c}$ & $49(19)$ \\
\hline Black & $234(60)$ & $54(43)$ & $175(67)$ \\
\hline Hispanic & $32(8)$ & $11(9)$ & $21(8)$ \\
\hline Other $^{e}$ & $21(5)$ & $6(5)$ & $15(6)$ \\
\hline \multicolumn{4}{|l|}{ Education } \\
\hline High school degree/GED or less & $223(57)$ & $57(45)^{c}$ & $161(72)$ \\
\hline Some college/vocational degree & $131(33)$ & $44(35)$ & $86(33)$ \\
\hline 4 year college graduate or more & $38(10)$ & $25(20)$ & $13(5)$ \\
\hline \multicolumn{4}{|l|}{ Employment } \\
\hline Unemployed & $231(59)$ & $81(64)$ & $146(56)$ \\
\hline Employed & $161(41)$ & $45(36)$ & $114(44)$ \\
\hline \multicolumn{4}{|l|}{ Marital status } \\
\hline Married & $28(7)$ & $7(6)$ & $21(8)$ \\
\hline Member of unmarried couple & $305(81)$ & $98(83)$ & $201(80)$ \\
\hline Single & $44(12)$ & $13(11)$ & $31(12)$ \\
\hline \multicolumn{4}{|l|}{ Insurance coverage } \\
\hline No & $199(50)$ & $72(58)$ & $124(47)$ \\
\hline Yes & $193(50)$ & $53(42)$ & $138(53)$ \\
\hline \multicolumn{4}{|l|}{ Marijuana use in the past year } \\
\hline No & $208(53)$ & $39(31)^{c}$ & $168(64)$ \\
\hline Yes & $182(47)$ & $86(69)$ & $93(36)$ \\
\hline \multicolumn{4}{|l|}{ Other drug $^{f}$ use in the past year } \\
\hline No & $334(87)$ & $90(73)^{c}$ & $241(93)$ \\
\hline Yes & $52(13)$ & $33(27)$ & $19(7)$ \\
\hline
\end{tabular}

${ }^{a}$ Data do not always sum up to total sample size due to missing data for specific variable.

${ }^{b}$ Defined if AUDIT score $>=8$ or binge drinking at least once monthly. $c_{p}<0.01$.

${ }^{d} \mathrm{P}<0.05$.

e Include Asian, Native Hawaiian/Pacific Islander, and American Indian/Alaskan Native.

Include cocaine or crack, stimulants, anxiety medication or sedatives, prescription pain medications, hallucinogens, inhalants, and opioids.

percent of hazardous drinkers currently owned a cell phone, and 91\% reported use of any cell phone application: text messages (90\%), taking pictures (90\%), 
Table 2 ICT use among persons attending two non-urban STD clinics in Florida, USA

\begin{tabular}{|c|c|c|}
\hline ICT use & $\begin{array}{l}\text { Total }^{a} \\
(n=396) \\
N(\%) \\
\end{array}$ & $\begin{array}{l}\text { Hazardous drinkers } \\
(n=126) \\
N(\%)\end{array}$ \\
\hline Have internet access at least monthly? ${ }^{c}$ & $363(93)$ & $118(94)$ \\
\hline Have an email account? & $306(80)$ & $102(82)$ \\
\hline Check email account at least once daily? & $180(53)$ & $67(58)$ \\
\hline Currently own a cell phone? & $335(87)$ & $105(85)$ \\
\hline Use cell phone applications? $^{d}$ & $366(94)$ & $114(91)$ \\
\hline Enjoy playing a video game? & $239(69)$ & $79(66)$ \\
\hline Play any video game console at least once monthly? & $230(59)$ & $89(71)$ \\
\hline Cell phone conversations are private? & $330(84)$ & $107(86)$ \\
\hline Texting messages are private? & $325(84)$ & $107(86)$ \\
\hline During your waiting time at clinic visits, would you be willing to play health related video games? & $265(69)$ & $90(73)$ \\
\hline $\begin{array}{l}\text { Would you be comfortable with receiving a reminder that you have STD results available with } \\
\text { email or text messages? }\end{array}$ & $156(43)$ & $49(41)$ \\
\hline Would you be comfortable with receiving your actual test results with email or text messages? $?^{f}$ & $71(19)$ & $27(23)$ \\
\hline
\end{tabular}

${ }^{a}$ Data do not always sum up to total sample size due to missing data for specific variable.

${ }^{b}$ Defined if AUDIT score $>=8$ or binge drinking at least once monthly.

Include internet access at home, work, school, library, or the friend's house.

${ }^{d}$ Include downloading ringtones, music, games, sending text message, or taking pictures.

e Include Nintendo Wii, Playstation 2 or 3, Xbox360, Gameboy, and PS.

${ }^{f}$ Proportion was computed based on respondents who reported having an email account or owning any cell phone.

downloading ringtones (71\%), music (58\%) and games (45\%). More than two thirds (73\%) of them were willing to play health-related video games during their clinic waiting time, slightly higher than the entire sample (69\%). Generally, there was no significant difference in using any modality of ICT among hazardous drinkers as compared with non-hazardous drinkers except for self-reported playing any video game at least once monthly (71\% vs. 53\%, $\mathrm{P}<0.01)$.

\section{Privacy concerns of ICT use}

The majority of hazardous drinkers agreed that either cell phone conversations (86\%) or text messages (86\%) were private. Among those who reported having an email account and/or owning any cell phone, $41 \%$ reported feeling comfortable receiving email/text message reminders for their STD test results readiness. In contrast, most of them (77\%) might not feel comfortable receiving test results via email/text messages.

\section{Factors associated with four modalities of ICT use}

Table 3 showed the associations between socio-demographic characteristics and use of four modalities of ICT, including cell phone, internet, email and video games. The multivariable logistic regression model found significant associations between multifunction cell phone use and younger age (14-24 vs. 35+, Adjusted Odds Ratio (AOR) =7.8, 95\% CI (Confidence Interval): 1.8, 32.9; 25-34 vs. 35+, $\mathrm{AOR}=6.4,95 \% \mathrm{CI}: 1.4,29.9)$. Similarly, greater odds of monthly internet use were found among respondents who were younger (14-24 vs. $35+, \mathrm{AOR}=11.4,95 \%$ CI: 1.4, 95.5). Higher level of education was the only variable associated with increased odds of daily email use when controlling for other socio-demographic characteristics. The multivariable model found increased odds of monthly video game playing among males and those with younger age.

\section{Discussion}

Hazardous alcohol consumption was common in this sample of persons attending two non-urban STD clinics in the Southeastern United States: approximately one third of participants met hazardous drinking criteria. We found overall high rates of accessibility and utilization of various types of ICT, indicating a strong potential for the integration of ICT-based intervention into healthcare delivery in STD clinic settings. For example, information relevant to STD/HIV prevention could be administered via ICT application (i.e. web-based) to STD clinics attendees without the presence of healthcare providers. Similarly, the ICT-based program may help healthcare providers identify individuals with drinking problems and even provide brief interventions to those at increased risk of acquiring or spreading STD. In addition, most of the respondents indicated that they were willing to try health-related video games during their waiting time. While emails or text messaging may work for the purpose of notifying whether STD test results are ready, 
Table 3 Factors associated with ICT use among 126 hazardous drinkers ${ }^{a}$

\begin{tabular}{|c|c|c|c|c|}
\hline Characteristics & $\begin{array}{l}\text { Multifunction cell phone use } \\
\text { AOR }(95 \% \mathrm{Cl})^{b}\end{array}$ & $\begin{array}{l}\text { Monthly internet use } \\
\text { AOR }(95 \% \mathrm{Cl})\end{array}$ & $\begin{array}{l}\text { Daily email use } \\
\text { AOR }(95 \% \mathrm{Cl})\end{array}$ & $\begin{array}{l}\text { Monthly video game playing } \\
\text { AOR }(95 \% \mathrm{Cl})\end{array}$ \\
\hline \multicolumn{5}{|l|}{ Gender } \\
\hline Male & $-^{c}$ & - & - & $5.2(2.2,12.6)$ \\
\hline Female & & & & Ref \\
\hline \multicolumn{5}{|l|}{ Age (years) } \\
\hline $14-24$ & $7.8(1.8,32.9)$ & $11.4(1.4,95.5)$ & $1.8(0.4,8.4)$ & $29.7(2.9,301.3)$ \\
\hline $25-34$ & $6.4(1.4,29.9)$ & $13.6(0.99,186.5)$ & $1.2(0.2,6.1)$ & $32.6(3.0,358.0)$ \\
\hline $35+$ & Ref & Ref & Ref & Ref \\
\hline \multicolumn{5}{|l|}{ Race } \\
\hline White & - & - & $0.1(0.0,1.4)$ & - \\
\hline Black & & & $1.3(0.1,36.2)$ & \\
\hline Hispanic & & & $1.0(0.1,13.1)$ & \\
\hline Other $^{d}$ & & & Ref & \\
\hline \multicolumn{5}{|l|}{ Education } \\
\hline High school degree/GED or less some & Ref & Ref & Ref & - \\
\hline College/vocational degree & $2.4(0.8,7.7)$ & $4.0(0.4,40.0)$ & $12.9(3.7,45.7)$ & \\
\hline 4 Year college graduate or more & $9.1(0.9,86.9)$ & $2.9(0.2,54.7)$ & $14.2(1.6,123.8)$ & \\
\hline \multicolumn{5}{|l|}{ Employment } \\
\hline Unemployed & Ref & - & Ref & - \\
\hline Employed & $2.1(0.6,7.2)$ & & $1.6(0.5,5.3)$ & \\
\hline \multicolumn{5}{|l|}{ Marital status } \\
\hline Married & - & $0.3(0.0,16.1)$ & - & $3.4(0.1,76.2)$ \\
\hline Member of unmarried couple & & $0.7(0.1,8.9)$ & & $1.5(0.4,5.9)$ \\
\hline Single & & Ref & & Ref \\
\hline \multicolumn{5}{|l|}{ Insurance } \\
\hline No & Ref & Ref & - & - \\
\hline Yes & $2.2(0.7,6.9)$ & $7.9(0.7,94.7)$ & & \\
\hline
\end{tabular}

${ }^{a}$ Defined if AUDIT score $>=8$ or binge drinking at least once monthly.

${ }^{b} \mathrm{AOR}$ indicates adjusted odds ratio; $\mathrm{Cl}$, confidence interval.

Variables not included in multivariable logistic regression models since statistically insignificance in bivariate analysis.

${ }^{d}$ Include Asian, Native Hawaiian or Pacific Islander, and American Indian/Alaskan Native.

Significant associations $(\mathrm{P}<0.05)$ are highlighted in boldface.

it was generally not acceptable in terms of the delivery of actual results. It is not surprising to see that age and levels of education play a major role in influencing the utilization of ICT. Thus, researchers should continuously consider these two factors in any design and development of health intervention on the basis of ICT.

The prevalent internet use found in this study is consistent with prior work based on general STD patients from urban clinical settings [12,13]. Web-based screening and brief intervention to address alcohol misuse have already been evaluated and have shown promising results in some populations. For example, a doubleblind, randomized trial conducted in college students showed that the 6-week web-based brief intervention significantly reduced alcohol consumption and fewer personal problems, while these effects were not persistent after treatment ended [17].

A high rate of cell phone ownership was reported among hazardous drinkers. This finding is consistent with the results from a recent study assessing cell phone use among 266 patients receiving substance abuse treatments from 8 psychological or opioid-replacement therapy clinics [18]. Cell phone-based health interventions have been examined for up to 12 clinical areas, ranging from smoking cessation programs, pediatric vaccination reminders, to hypertension, diabetes and asthma management, whereas similar studies are lacking in the field of alcohol abuse prevention and intervention [19]. In addition, several realistic concerns have been raised regarding adoption of cell phone -based health 
interventions: costs of development and implementation, potential abuse of short message services (SMS) for things irrelevant to study, and lack of reimbursement for health professionals' involvement and extra time commitment. Nevertheless, our study suggests pervasive use of cell phone among STD patients, especially for those with hazardous drinking. With the flexibility of combining voice and text messaging with interactive multimedia components, cell phone technology could increase the likelihood of successfully delivering health behavioural interventions to traditionally hard-to-reach population, such as those with alcohol misuse.

Multivariable regressions found no significant racial discrepancy in terms of ICT use. However, a "digital divide" appears to exist among people from different age groups and levels of education. Interestingly, our regression results suggest that males are much more likely to play video game than females. Health-related video games playing may provide a novel approach to deliver behavioural education and intervention. A video game-based health intervention could be offered via game consoles or computers located in clinical facilities or cell phones to reach broader populations. However, our results show that males are more likely to play video game than females, which may lead to gender disparity in access to care. Future research exploring video games as a means to implement health interventions should consider this and try to adjust the design to ensure equal responses from both genders.

Our participants appear to be interested in playing a health-related video game during their waiting time at clinic visits. Meanwhile, they also disclose great concerns of receiving STD test results via either emails or text messages. It is noted that participants may only perceive text messaging private for ordinary communication, but not private enough for delivering information as sensitive as STD results. One potential solution to secure confidentiality of text messages is to add a security code to the phone or even to the message box. This function is commonly available in smartphones and could be easily achieved by using apps designed for this purpose.

Several limitations of this study should be noted. First, our findings of ICT use represent a sample in 2009, and may not necessarily reflect the current access and utilization of ICT among general STD clinic attendees and hazardous drinkers. Second, the results of this study may not be easily generalized to other geographic areas since this study is only based on two non-urban clinics located in the Southeastern US. However, we specifically evaluated the ICT use by subgroups to allow others to compare our findings to similar settings. Finally, our study is cross-sectional, and thus we can only state that different characteristics are associated with use of certain types of ICT but not predictive.

\section{Conclusions}

One third of persons attending two non-urban STD clinics were current hazardous drinkers, and even more used marijuana or other drugs. These findings reinforce the pressing need for intervention to address alcohol or substance abuse in STD clinic settings. Our study demonstrates commonality of ICT use among STD patients with hazardous drinking, which indicates the viability of using ICT to assist screening and behavioural intervention for alcohol misuse. Variations presented in ICT use and access across age groups, genders and education levels reflect the continued presence of a "digital divide". Clinicians and ICT program developers interested in creating ICT-based health interventions for alcohol and substance abuse intervention should be aware of and try to address it by including multiple ICT alternatives to avoid less representation of some sub-population, like females for video games playing. More research is needed to demonstrate the acceptability and effectiveness of different types of ICT-based interventions in the STD clinic settings or other venues that serve populations at high risk for substance abuse, HIV or other STDs.

\section{Abbreviations}

ICT: Information and communication technology; STD: Sexually transmitted disease; AUDIT: Alcohol use disorders identification test; AOR: Adjusted odds ratio; Cl: Confidence interval; GED: General educational development.

\section{Competing interests}

The authors declare that there are no competing interests in this study.

\section{Authors' contributions}

$\mathrm{XH}$ performed the data analysis and wrote the manuscript. VJD, JOC and RLC participated in the design of the study, collected the data and helped to draft the manuscript. All authors read and approved the final manuscript.

\section{Acknowledgements}

This study was partly founded by the University of Florida Opportunity Fund Award and NIH grant (U24-022002)

The authors wish to thank Jill Sonke for her assistance with early design of the study and Okafor Chukwuemeka for the revision of the manuscript.

\section{Author details}

Department of Epidemiology, University of Florida, Gainesville, FL, USA ${ }^{2}$ Department of Community Dentistry and Behavioral Science, University of Florida, Gainesville, FL, USA. ${ }^{3}$ Digital Worlds Institute, University of Florida, Gainesville, FL, USA. ${ }^{4}$ College of Medicine, University of Florida, Gainesville, $\mathrm{FL}$, USA.

Received: 31 March 2013 Accepted: 20 March 2014

Published: 26 March 2014

\section{References}

1. Hutton HE, McCaul ME, Chander G, Jenckes MW, Nollen C, Sharp VL, Erbelding EJ: Alcohol Use, anal Sex, and other risky sexual behaviors among HIV-infected women and Men. AIDS Behav 2013, 17(5):1694-1704

2. Cook RL, Clark DB: Is there an association between alcohol consumption and sexually transmitted diseases? A systematic review. Sex Transm Dis 2005, 32:156-164.

3. Cooper ML: Alcohol use and risky sexual behavior among college students and youth: evaluating the evidence. J Stud Alcohol Supp/ 2002, 14:101.

4. Celum CL, Bolan G, Krone M, Code K, Leone P, Spaulding C, Henry K, Clarke P, Smith M, Hook EW 3rd: Patients attending STD clinics in an evolving health 
care environment. Demographics, insurance coverage, preferences for STD services, and STD morbidity. Sex Transm Dis 1997, 24:599-605.

5. Kalichman SC, Cain D, Zweben A, Swain G: Sensation seeking, alcohol use and sexual risk behaviors among men receiving services at a clinic for sexually transmitted infections. J Stud Alcohol 2003, 64:564-569.

6. Zenilman JM, Hook EW 3rd, Shepherd M, Smith P, Rompalo AM, Celentano DD: Alcohol and other substance use in STD clinic patients: relationships with STDs and prevalent HIV infection. Sex Transm Dis 1994, 21:220-225.

7. Cook RL, Comer DM, Wiesenfeld HC, Chang C-CH, Tarter R, Lave JR, Clark DB: Alcohol and drug use and related disorders: an underrecognized health issue among adolescents and young adults attending sexually transmitted disease clinics. Sex Transm Dis 2006, 33:565-570.

8. Carroll KM, Ball SA, Martino S, Nich C, Babuscio TA, Nuro KF, Gordon MA, Portnoy GA, Rounsaville BJ: Computer-assisted delivery of cognitivebehavioral therapy for addiction: a randomized trial of CBT4CBT. Am J Psychiatry 2008, 165:881-888.

9. Marsch LA, Bickel WK, Grabinski MJ: Application of interactive, computer technology to adolescent substance abuse prevention and treatment. Adolesc Med State Art Rev 2007, 18:342-356. xii.

10. Bickel WK, Christensen DR, Marsch LA: A review of computer-based interventions used in the assessment, treatment, and research of drug addiction. Subst Use Misuse 2011, 46:4-9.

11. Rooke S, Thorsteinsson E, Karpin A, Copeland J, Allsop D: Computer-delivered interventions for alcohol and tobacco use: a meta-analysis. Addiction 2010, 105:1381-1390.

12. Samal L, Hutton HE, Erbelding EJ, Brandon ES, Finkelstein J, Chander G: Digital divide: variation in internet and cellular phone use among women attending an urban sexually transmitted infections clinic. J Urban Health 2010, 87:122-128.

13. Mark KE, Wald A, Drolette L, Golden MR: Internet and email use among STD clinic patients. Sex Transm Dis 2008, 35:960-965.

14. Reid MC, Fiellin DA, O'Connor PG: Hazardous and harmful alcohol consumption in primary care. Arch Intern Med 1999, 159:1681-1689.

15. Cook RL, Chung T, Kelly TM, Clark DB: Alcohol screening in young persons attending a sexually transmitted disease clinic. Comparison of AUDIT, CRAFFT, and CAGE instruments. J Gen Intern Med 2005, 20:1-6.

16. Naimi TS, Brewer RD, Mokdad A, Denny C, Serdula MK, Marks JS: Binge drinking among US adults. JAMA 2003, 289:70-75.

17. Kypri K, McCambridge J, Vater T, Bowe SJ, Saunders JB, Cunningham JA, Horton NJ: Web-based alcohol intervention for Māori university students: double-blind, multi-site randomized controlled trial. Addiction 2013, 108:331-338.

18. McClure EA, Acquavita SP, Harding E, Stitzer ML: Utilization of communication technology by patients enrolled in substance abuse treatment. Drug Alcohol Depend 2013, 129:145-150.

19. Krishna S, Boren SA, Balas EA: Healthcare via cell phones: a systematic review. Telemed J E Health 2009, 15:231-240

Cite this article as: Hu et al:: Utilization of information and communication technology (ICT) among sexually transmitted disease clinics attendees with coexisting drinking problems. BMC Research Notes 2014 7:178.

\section{Submit your next manuscript to BioMed Central and take full advantage of:}

- Convenient online submission

- Thorough peer review

- No space constraints or color figure charges

- Immediate publication on acceptance

- Inclusion in PubMed, CAS, Scopus and Google Scholar

- Research which is freely available for redistribution 